\title{
Long non-coding RNA EPB41L4A-AS2 inhibited non-small cell lung cancer proliferation and invasion and promoted cell apoptosis
}

\author{
J. SHU ${ }^{1, \star}$, S. $\mathrm{LI}^{1}$, Y. B. CHEN ${ }^{2}$, Q. F. ZHU ${ }^{1}$, X. H. YU \\ ${ }^{1}$ Department of Cardiothoracic Surgery, Taicang Affiliated Hospital of Soochow University, the First People's Hospital of Taicang, Taicang, China; \\ ${ }^{2}$ Department of Cardiothoracic Surgery, the Second Affiliated Hospital of Soochow University, Suzhou, China
}

*Correspondence: $z$ hang_clxz@163.com

Received July 13, 2017 / Accepted September 27, 2017

\begin{abstract}
This research investigates the expression of lncRNA EPB41L4A-AS2 in non-small cell lung cancer (NSCLC) and evaluates its influence on the proliferation, invasion and apoptosis of NSCLC. A total of 56 NSCLC tissues and corresponding adjacent tissue was collected. Quantitative Reverse transcription polymerase chain reaction (qRT-PCR) evaluated the lncRNA EPB41L4A-AS2 expression level in tissues and cell lines, and proliferating cell nuclear antigen (PCNA) protein level was determined by western blot assay. CCK8 assay, EdU assay, flow cytometry (FCM) and transwell assay were performed to access cell proliferation, apoptosis and invasion. EPB41L4A-AS2 expression was significantly downregulated in cancer tissues and cells compared with adjacent tissues and normal cells $(\mathrm{p}<0.05)$. After cells were transfected with pcDNA3.1-EPB41L4A-AS2, cell viability and PCNA protein level was decreased, and cells were arrested in the G0/G1 phase with a higher apoptosis rate. Transwell assay showed that over-expressed EPB41L4A-AS2 could reduce cells invasion ability. Low-level expression of EPB41L4A-AS2 is associated with poor survival in NSCLC and over-expression of lncRNA EPB41L4A-AS2 inhibits NSCLC cell proliferation and invasion and promotes cell apoptosis.
\end{abstract}

Key words: NSCLC, LncRNA EPB41L4A-AS2, proliferation, apoptosis, invasion

Lung cancer is one of the most common malignant tumors and retains the highest proportions of cancer-related death worldwide $[1,2]$. Non-small cell lung cancer (NSCLC) accounts for over $80 \%$ of all lung cancer cases [3]. While surgery, chemotherapy and radiotherapy remain major treatment options for NSCLC [4], treatment still presents challenges because of lung cancer cell metastasis and the lack of biomarkers for early-stage diagnosis [5]. Although significant progress has been made in NSCLC development and tumor genesis, the underlying molecular mechanisms still require elucidation. Correspondingly, National Cancer Institute records show that the 5-year overall survival (OS) rate for NSCLC patients is still only approximately $15 \%$. [6]. Therefore, understanding the underlying molecular mechanisms involved in NSCLC progress and development is vital for developing new specific diagnostic skills and designing more effective and individualized therapeutic strategies.

With the rapid development and innovation of sequencing technique in the past decade, numerous important projects have achieved great progress. These include The Cancer Genome Atlas (TCGA) and ENCyclopedia of DNA Elements
(ENCODE) which led to the discovery of long non-coding RNAs (lncRNAs) [7-9]. LncRNAs are non-coding RNAs over 200 nucleotides in length and widely expressed across the eukaryotic genome $[8,10]$. Because of the lack of protein encoding ability, lncRNAs were once regarded as cloning artifacts and transcriptional "noise" [11]. However, emerging research has shown that anomalous lncRNA expression is relevant in many diseases. $[12,13]$. More importantly, lncRNAs are provn regulators of tumorigenesis through participating in biological activities, such as proliferation, the epithelialmesenchymal transition process, drug resistance and apoptosis modulation [14-16]. Several studies have also revealed that lncRNAs act as suppressor genes or oncogenes [17, 18].

The lncRNA EPB41L4A-AS2 is an antisense lncRNA located at the genome $5 \mathrm{q} 22.2$ region [19]. While few studies have reported association or biological function of $\operatorname{lncRNAs}$ EPB41L4A-AS2 in cancers or other human diseases, $\mathrm{Xu}$ et al. found it played a role as a tumor suppressor in breast cancer and other solid tumors [20]. However, the biological function, underlying mechanism and even expression pattern of EPB41L4A-AS2 in NSCLC are still unknown. 
To study the clinical correlation of lncRNA EPB41L4AAS2 and biological role of lncRNA EPB41L4A-AS2 in NSCLC, we examined lncRNA EPB41L4A-AS2 expression and its relationship with pathological and clinical features of lung tumor samples. Moreover, we used varieties of cell experiments, including qRT-PCR, western blot, CCK8, flow cytometry (FCM) and transwell assays, to further illustrate the function of EPB41L4A-AS2 in NSCLC. Herein, the lncRNA EPB41L4A-AS2 was significantly down-regulated in lung tumor cells compared to corresponding adjacent tissues. In addition, we revealed that EPB41L4A-AS2 could inhibit NSCLC proliferation and invasion, affect the cell cycle and promote cell apoptosis. This suggests that EPB41L4A-AS2 could act as an independent predictor or therapeutic target for NSCLC patients.

\section{Materials and methods}

Clinical specimens. All 56 NSCLC and adjacent tissues were obtained from patients who accepted surgical treatment at the First People's Hospital of Taicang from February 2015 to June 2016. No radiotherapy or chemotherapy was performed before the operation and all specimens were confirmed by pathologists. This research was permitted by the First People's Hospital of Taicang Medical Ethics Committee and we obtained written informed consent from all patients. All tissue specimens were snap-frozen immediately in liquid nitrogen and stored at $-80^{\circ} \mathrm{C}$.

TCGA data analysis. The clinical data was downloaded on TCGA database (https://cancergenome.nih.gov/). Prognosis data was analyzed and the OS curve and disease-free survival (DFS) curve correlating with EPB41L4A-AS2 in NSCLC was plotted by R studio (TIBCO, USA).

Cell culture. Normal human bronchial epithelial cell line (16HBE), NSCLC cell line (SK-MES-1) and lung adenocarcinoma cell lines (HCC827, A549 and NCI-H1975) were proven by short tandem repeat (STR) analysis. Sample cells were bought from the Cell Biology of the Chinese Academy of Sciences. SK-MSE-1 and A549 cells were cultured at DMEM (Dulbecco's Modified Eagle's Medium) with fetal bovine serum (FBS, Invitrogen, USA) at concentration of $10 \%$ and RPMI-1640 medium included with $10 \%$ FBS (Invitrogen, USA) was applied to culture 16HEB, HCC827 and NCI-H1975 cell lines. All cells were placed in a $37^{\circ} \mathrm{C}$ incubator with humidity $95 \%$ and $\mathrm{CO}_{2}$ concentration of $5 \%$.

Plasmid construction and cell transfection. The PCR primers, IncRNA EPB41L4A-AS2 cDNA and siRNA used in this experiment were synthesized by Shanghai Bioengineering Engineering Co., Ltd. NCI-H1975 and A549 cell lines were transfected with the EPB41L4A-AS2 overexpression plasmid and si-EPB41L4A-AS2, respectively by Lipofectamine 2000 (Invitrogen, USA). The NCI-H1975 cell line was established in three groups: pcDNA3.1-EPB41L4AAS2 group (transfected with pcDNA3.1-EPB41L4A-AS2 plasmid), NC group (transfected with pcDNA3.1 blank plasmid) and control group (without transfection). The A549 cells were also established in three groups: si-EPB41L4A-AS2 group (transfected with EPB41L4A-AS2 siRNA), NC group (transfected with negative control siRNA) and control group (without transfection).

CCK8 assay. Cells were collected after 24-hour stable transfection and placed at $2 \times 10^{4}$ cells $/ \mathrm{ml}$ density in 96-well plates. At $0,1,2$, and 3 days, CCK-8 $(10 \mathrm{ml} /$ well $)$ reagent (Beyotime, China) was added to each well. Absorbance at $450 \mathrm{~nm}$ was measured by automatic enzyme-linked immune detector after 2 hours incubation. The cell growth curve was plotted with time as the horizontal axis and the OD value as the vertical axis. The experiment was performed in triplicate.

EdU assay. Transfected cells were seeded in 96-well plates and cultured. Briefly, cells were incubated with EdU labeling medium at moderate concentration for 2 hours and then fixed with PBS ( $50 \mu \mathrm{l}$, containing $4 \%$ paraformaldehyde), for 30 minutes, washed for 5 minutes with PBS $(100 \mu \mathrm{l})$, and stained with $100 \mu \mathrm{l}$ Apollo solution for 30 minutes at room temperature in the dark. The cells were stained, washed with $0.5 \%$ TritonX-100 in PBS $(100 \mu \mathrm{l})$ for 10 minutes each time, and the percentage of EdU positive cells was detected.

Flow cytometry. Cells were obtained after $48 \mathrm{~h}$ transfection with $0.2 \%$ trypsin and washed with PBS and then fixed with $70 \%$ ethanol overnight at $4{ }^{\circ} \mathrm{C}$. PBS then washed-out the fixative solution and fixed cells were re-suspended in PBS for 10 minutes. Apoptosis was detected by AnnexinV-FITC/PI kit (Beyotime, China). Cells were re-suspended by PBS and Annexin V-FITC added $(5 \mu \mathrm{l}) /$ propidium iodide $(5 \mu \mathrm{l})$ for 10 minutes Finally, the cells were incubated for 30 minutes at $4^{\circ} \mathrm{C}$ in the dark. Both cell cycle and apoptosis were measured by FACS Calibur type flow cytometry with Cell Quest software. Each study was in triplicate.

Transwell assay. Cell invasion activity was evaluated by transwell chambers following the manufacturer's instruction. Matrigel $(50 \mathrm{mg} / \mathrm{l})$ coated the upper chamber and was allowed to solidify at $37^{\circ} \mathrm{C}$ overnight. After solidification, $200 \mathrm{ml}$ of serum-free medium was poured into the chamber above $7{ }^{\circ} \mathrm{C}$. Trypsin $(0.05 \%)$ was used to digest cells and adjust the fluid density to $1 \times 10^{6} / \mathrm{ml}$. After 48 -hour culture, $500 \mathrm{ml}$ of $10 \%$ FBS complete medium was added and cells were fixed in $4 \%$ paraformaldehyde. Finally, the cells were soaked with $0.1 \%$ crystal violet solution and invasive cells were counted after resin seal by microscope (200x). Each study was repeated three times.

Western blot. Cells were resolved in radio immunoprecipitation assay (RIPA) protein lysis buffer (Cell signaling Technology). After the protein concentration was detected by bicinchoninic acid (BCA), the lysates were loaded onto $10 \%$ SDS-PAGE. Protein samples were transferred onto polyvinylidene fluoride (PVDF) membranes at constant voltage of $15 \mathrm{~V}$ and soaked in $5 \%$ skim milk for 2 hours. The membranes were then incubated with the primary antibody (rabbit anti-human PCNA monoclonal antibody, ZSGB Company) diluted at $1: 1200$ and placed at $4^{\circ} \mathrm{C}$ overnight. 
Tris Buffered Saline Tween (TBST) was applied to wash the membranes and the membranes were then incubated with secondary antibody (HRP labeled goat anti-mouse IgG, ZSGB Company) with a dilution ratio of 1:2000 at room temperature for 2 hours. After washing three times with TBST for 10 minutes, samples were analyzed by Alpha-Innotech (San Leandro, CA) gel imager. Results were quantitatively analyzed by ImageJ software with glyceraldehyde-3-phosphate dehydrogenase (GAPDH) as the internal reference.

Real time-PCR. Tissues and cells were extracted by Trizol $^{\circledR}$ Reagent (Invitrogen, USA) following the manufacturer's protocol. After washing, the total RNA was extracted and subjected to RNA identification by agarose gel electrophoresis. The RNA was then transcribed into cDNA by TaKaRa reverse transcription kit (TaKaRa, China) and subjected to RT-PCR reaction. The primer sequence was: EPB41L4AAS2 forward: 5'-GCAAGTGTTGAAGGACGACGAT-3', reverse: 5'-CAAGGAGGCATACACGGAGTT-3', GAPDH forward: 5'-GTCAACGGATTTGGTCTGTATT-3', reverse: 5'AGTCTTCTG-GGTGGCAGTGAT-3'. Relative quantification was performed by the comparative threshold cycle $\left(2^{-\Delta \Delta C t}\right)$ method with GAPDH as the internal reference.

Statistics analysis. All statistical analyses were by Statistical Package for the Social Sciences version 16.0 software (SPSS Inc., Chicago, IL, USA). Measurement dates are calculated as the mean \pm standard deviation (SD). The t-test was utilized to compare the metrological data between the two groups and the unpaired t-test was applied when

Table 1. Association analysis between EPB41L4A-AS2 expression and clinicopathologic parameters.

\begin{tabular}{lcccc}
\hline $\begin{array}{l}\text { Clinicopathologic } \\
\text { parameters }\end{array}$ & \multicolumn{2}{c}{$\begin{array}{c}\text { EPB41L4A-AS2 } \\
\text { expression }\end{array}$} & $\begin{array}{c}\text { Number } \\
\text { of cases }\end{array}$ & p-value \\
\cline { 2 - 3 } & Low & High & & 0.6426 \\
\cline { 1 - 2 } Age (years) & 12 & 12 & 24 & \\
$\quad \leq 60$ & 14 & 18 & 32 & \\
$\quad>60$ & 13 & 11 & 24 & \\
Gender & 13 & 19 & 32 & \\
$\quad$ Male & & & & 0.3146 \\
$\quad$ Female & 11 & 9 & 20 & \\
Diameter & 24 & 12 & 36 & \\
$\quad 33$ & & & & 0.1264 \\
$\quad 3$ & 21 & 9 & 30 & \\
Lymph node metastasis & 13 & 13 & 26 & \\
$\quad$ Yes & & & & $0.0005^{*}$ \\
$\quad$ No & 5 & 16 & 21 & \\
TNM stage & 25 & 10 & 35 & \\
$\quad$ I-II & & & & 0.4102 \\
$\quad$ III-IV & 14 & 16 & 30 & \\
Degree of differentiation & 15 & 11 & 26 & \\
$\quad$ Well and moderately & & & & \\
$\quad$ Poorly & & & & \\
\hline
\end{tabular}

Chi-square test $\left({ }^{*} \mathrm{p}<0.05\right)$ normal distribution was lacking. ANOVA was used in multiple groups with $\mathrm{p}<0.05$ statistically significant.

Ethics approval and consent to participate. All procedures were conducted in accordance with the Declaration of Helsinki and approved by the Ethics Committee of the First People's Hospital of Taicang. All participating patients consented to their inclusion in this study.

\section{Results}

Expression of EPB41L4A-AS2 in tissues and cell lines. The RT-PCR results showed that EPB41L4A-AS2 expression in lung cancer tissues was obviously lower than that in adjacent tissues $(\mathrm{p}<0.05$, Figure $1 \mathrm{~A})$, and its expression correlated with the TNM stage ( $\mathrm{p}<0.05$, Table 1$)$. EPB41L4AAS2 expression was down-regulated in A549, SK-MES-1, HCC827 and NCI-H1975 compared to the bronchial epithelial cell line control $(16 \mathrm{HBE})(\mathrm{p}<0.05$, Figure $1 \mathrm{~B})$. We then chose NCI-H1975 and A549 cell lines for our following experiments.

Correlation between EPB41L4A-AS2 expression and survival rate. Patient prognostic indicators and the relative EPB41L4A-AS2 expression level on the TCGA database were analyzed, and results revealed that the fraction survival of patients correlated with the EPB41L4A-AS2 expression level. Low EPB41L4A-AS2 expression was associated with poor overall survival and disease-free survival in NSCLC $(\mathrm{p}<0.05$, Figure $2 \mathrm{~A}, 2 \mathrm{~B})$, thus indicating that EPB41L4A-AS2 may have clinical importance in NSCLC.

LncRNA EPB41L4A-AS2 inhibits proliferation and invasion of NSCLC cells. EPB41L4A-AS2 expression in the H1975 cells significantly increased after they were transfected with pcDNA3.1-EPB41L4A-AS2, and the expression level of EPB41L4A-AS2 in A549, which was transfected with si-EPB41L4A-AS2, was significantly reduced ( $<<0.05$, Figure 3A). CCK-8 assay and EdU assay revealed that H1975 cell viability decreased when EPB41L4A-AS2 was overexpressed, while the cell viability of A549 cells increased in the si-EPB41L4A-AS2 group compared with control group $(p<0.05$, Figure $3 B-3 D)$. We then detected expression of PCNA which was the molecular marker for cell proliferation. Western blot results revealed that PCNA protein level decreased in the H1975 cell group when EPB41L4A-AS2 was over-expressed, and the PCNA protein level in si-EPB41L4AAS2 A549 group was higher than in the control group ( $\mathrm{p}<0.05$, Figure $4 \mathrm{~A}$ ). The Transwell assay also indicated that overexpression of EPB41L4A-AS2 in H1975 cells significantly inhibited tumor cell invasive ability, while EPB41L4A-AS2 knockdown in A549 cells promoted cell invasion ( $<<0.05$, Figure 4B). All results confirmed that EPB41L4A-AS2 played a role as tumor suppressor gene in regulating NSCLC cell proliferation and invasion.

LncRNA EPB41L4A-AS2 affected cell cycle and promoted cell apoptosis. Flow cytometry analysis highlighted that EPB41L4A-AS2 over-expression induced 

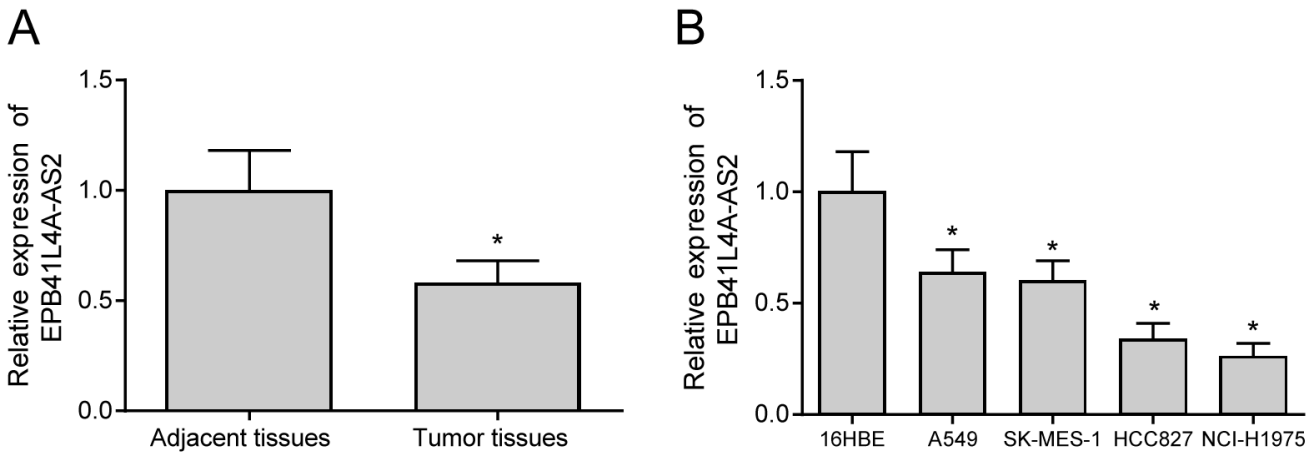

Figure 1. Expression of EPB41L4A-AS2 in non-small cell lung cancer (NSCLC) tissues and cells. (A) Differential expression of EPB41L4A-AS2 in NSCLC tissues and adjacent tissues was detected by RT-PCR. ${ }^{\star} \mathrm{p}<0.05$ compared with adjacent tissues. (B) EPB41L4A-AS2 expression in each cell line was detected by RT-PCR. ${ }^{\star} \mathbf{p}<0.05$ compared with $16 \mathrm{HBE}$ group.
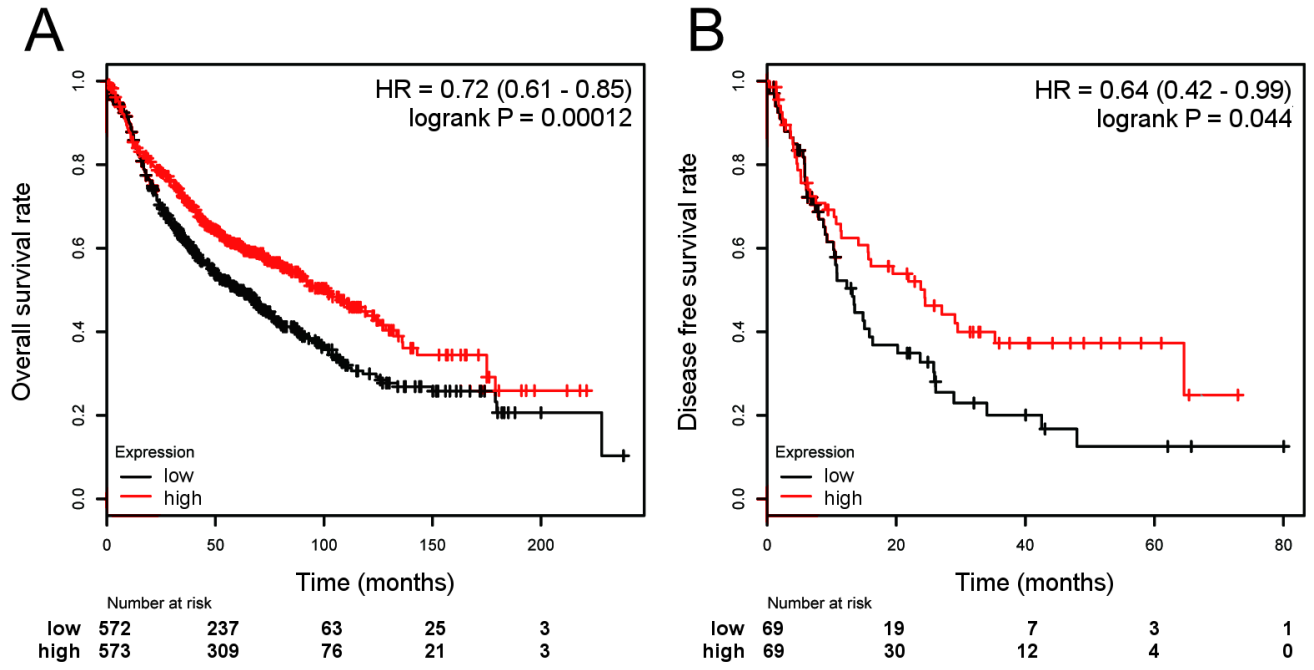

Figure 2. Expression of low levels of EPB41L4A-AS2 is associated with poor survival in NSCLC. (A) OS of NSCLC correlating with EPB41L4A-AS2. (B) DFS of NSCLC correlating with EPB41L4A-AS2.

significant increase in H1975 cell percentage in the G0/G1 phase $(\mathrm{p}<0.05)$. Thus, cells were arrested in the G0/G1 phase, while EPB41L4A-AS2 knockdown reduced the proportion of A549 cells in this phase $(\mathrm{p}<0.05)$ and promoted cell proliferation (Figure 5A).

Flow cytometry also showed that over-expression of EPB41L4A-AS2 could promote cell apoptosis in H1975 cells (Figure $5 \mathrm{~B}$ ); and the above results therefore indicated that EPB41L4A-AS2 could suppress NSCLC cell proliferation by inducing G0/G1 arrest and apoptosis.

\section{Discussion}

Scientific research has found that over $75 \%$ of genomes are transcribed to RNA in the process of mammalian transcription, but only $2.3 \%$ of those acted as coding transcripts and the rest were lncRNAs [21-24]. Despite growing under- standing of lncRNAs' role in cancer biology, it remains a huge project for scientists to prove their effects.

The occurrence and development of NSCLC is still one of the main threats to human life [25], and although different types of new drugs have been developed for its treatment, the prospect remains unoptimistic [26]. Scientists have focused on pathogenic factors in NSCLC because lncRNA appeared a vital regulating factor [27], and research revealed that lncRNA can exert its own special biological function in regulating the expression of genes related to tumor cell proliferation, apoptosis, tissue differentiation and cancer pathogenesis [28]. A number of lncRNAs have been reported to have irreplaceable roles in many human cancers; these include NSCLC $[29,30]$.

For example, IncRNA AK126698 can regulate the Wnt pathway and thus confer cisplatin which can then enhance the NSCLC treatment clinical effect [31]. LncRNA MALAT-1 

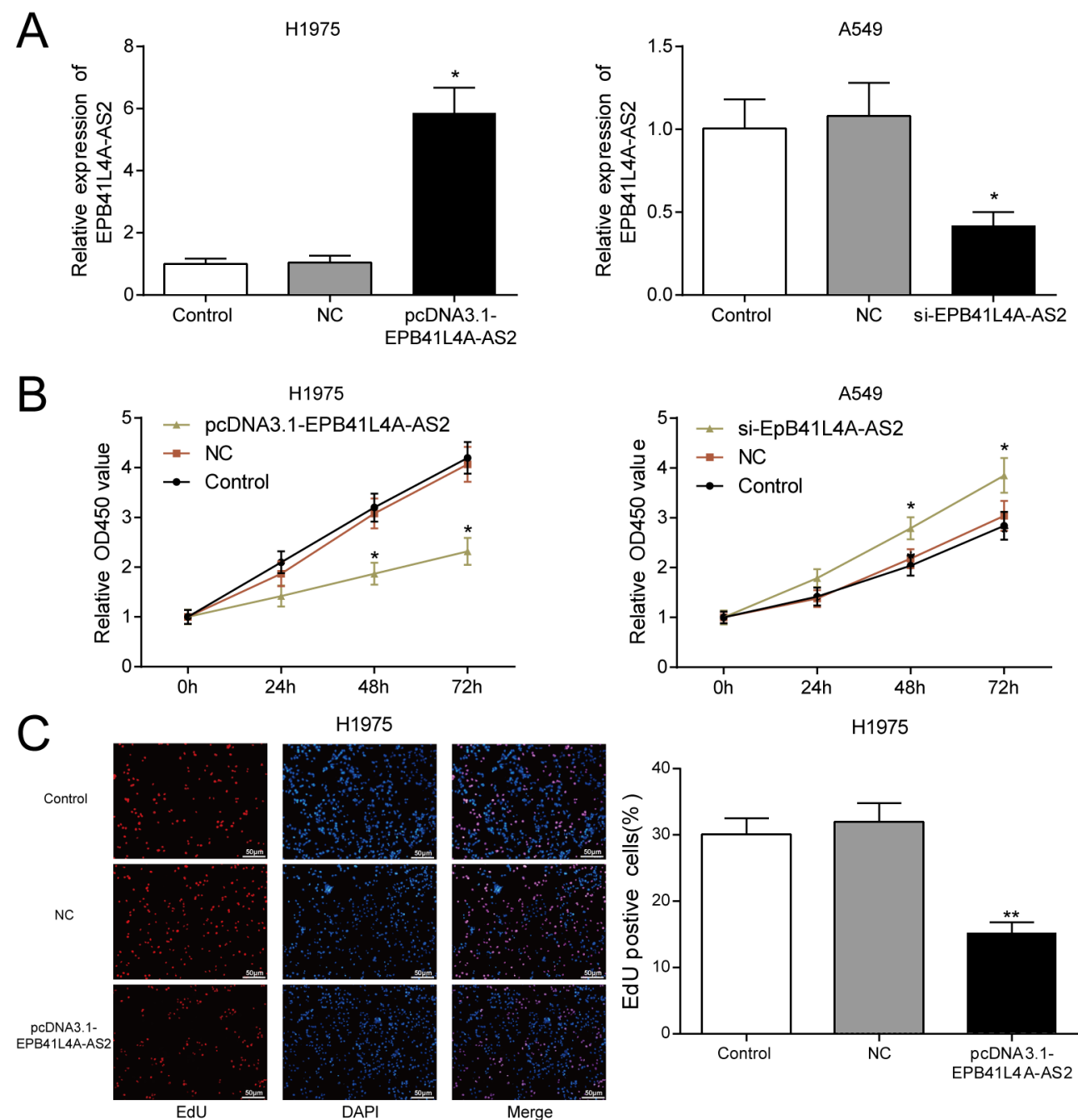

$\mathrm{H} 1975$
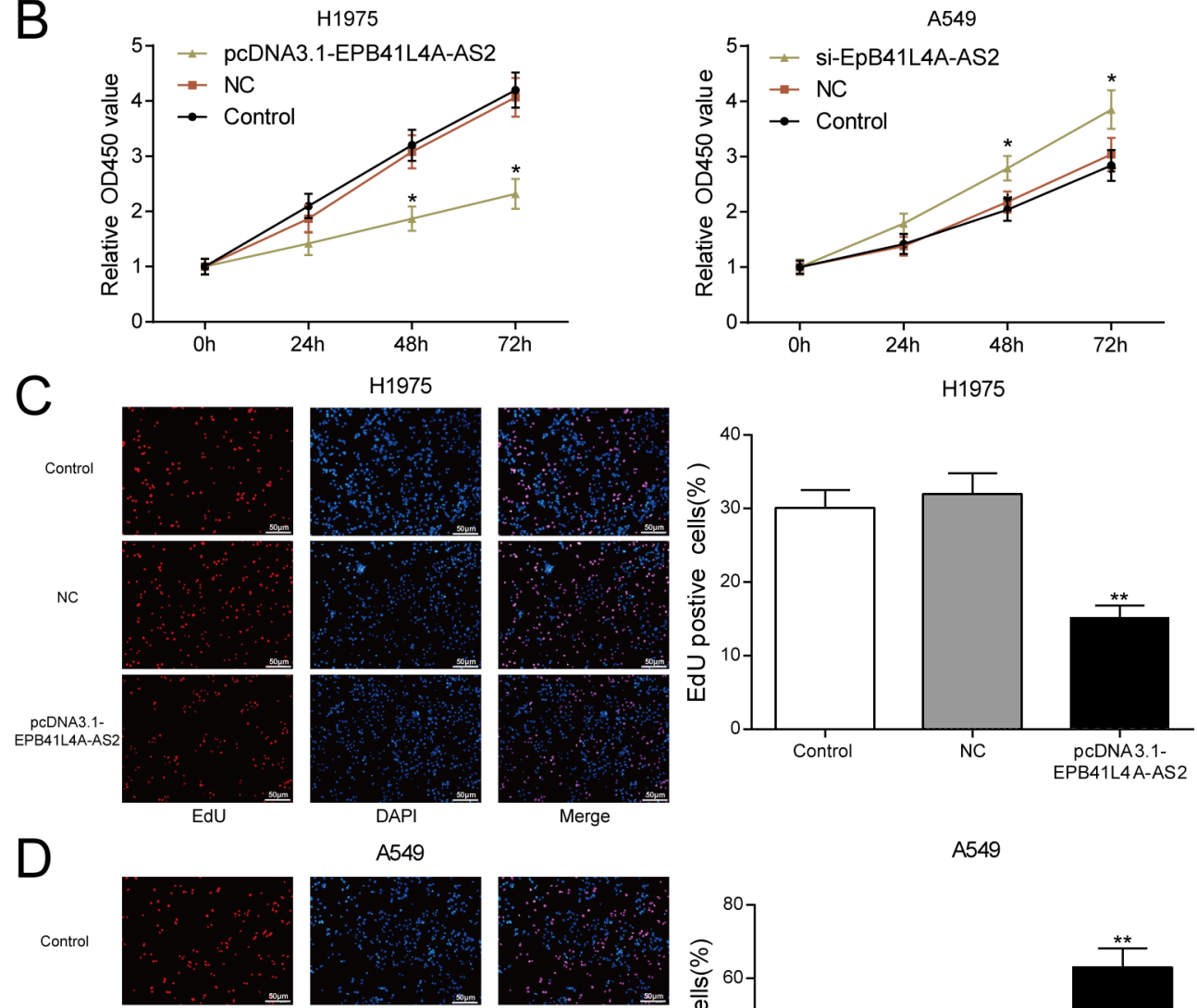

A549
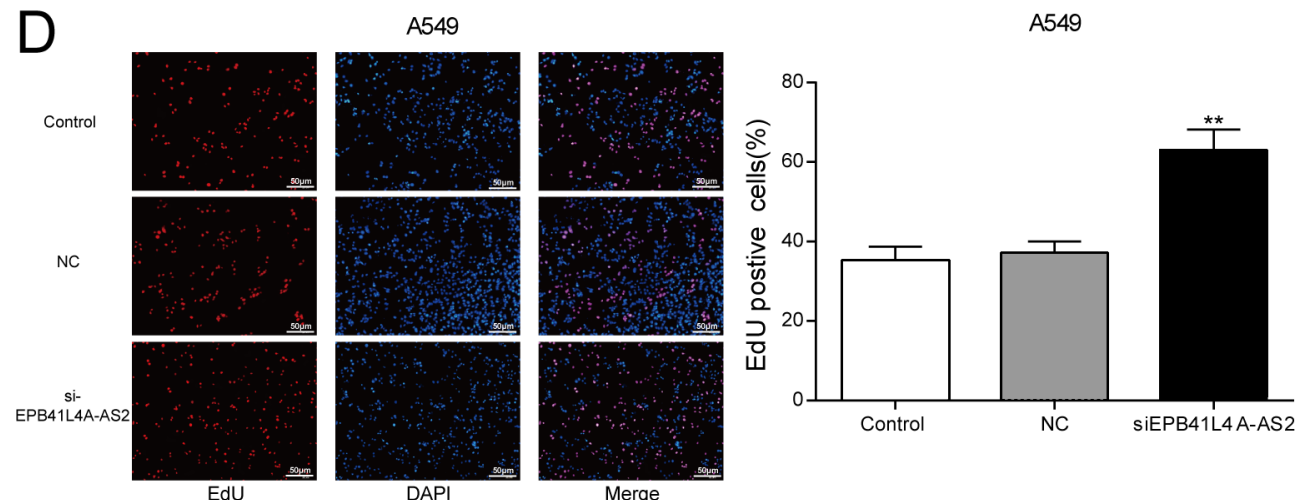

Figure 3. EPB41L4A-AS2 inhibits cell proliferation. (A) The expressions of LncRNA EPB41L4A-AS2 in H1975 and A549 cells were analyzed by qRTPCR. (B) CCK8 assay measured the proliferation of H1975 and A549 cells. (C) EdU assay measured the proliferation of H1975 cells. (D) EdU assay measured the proliferation of A549 cells. ${ }^{\star} \mathrm{p}<0.05$ compared with control groups. ${ }^{* *} \mathrm{p}<0.01$ compared with control groups.

was related to NSCLC cells and it has now been recognized as a biological marker [32]. In addition, over-expressed lncRNA HOTAIR acts as a novel marker, which regulates NSCLC cell metastasis and invasion through down-regulation of HOXA5 [33]. Herein, we have also shown that lncRNA EPB41L4AAS2 is related to NSCLC development 
A
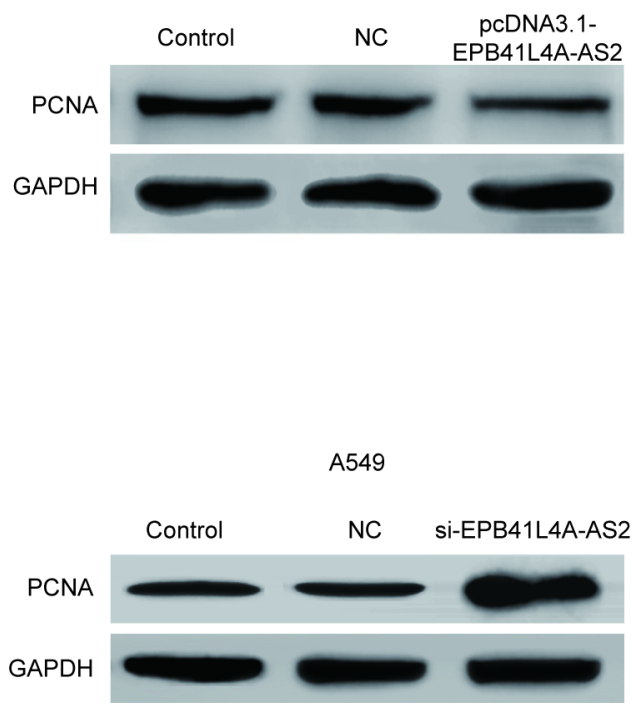

B
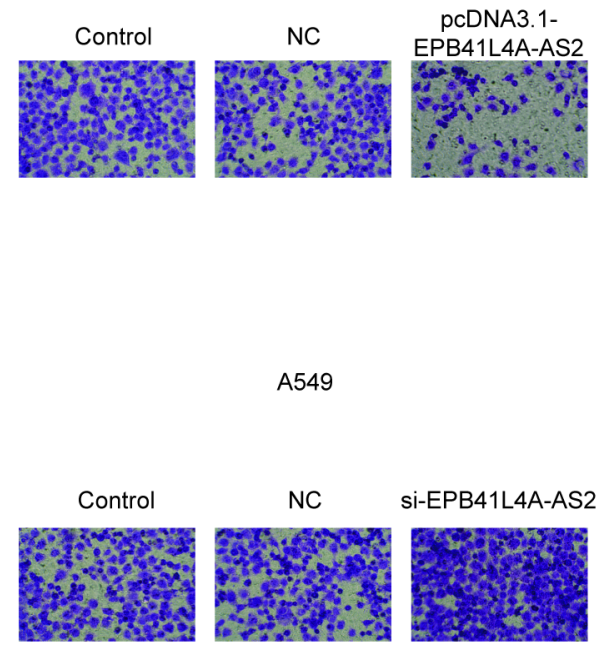
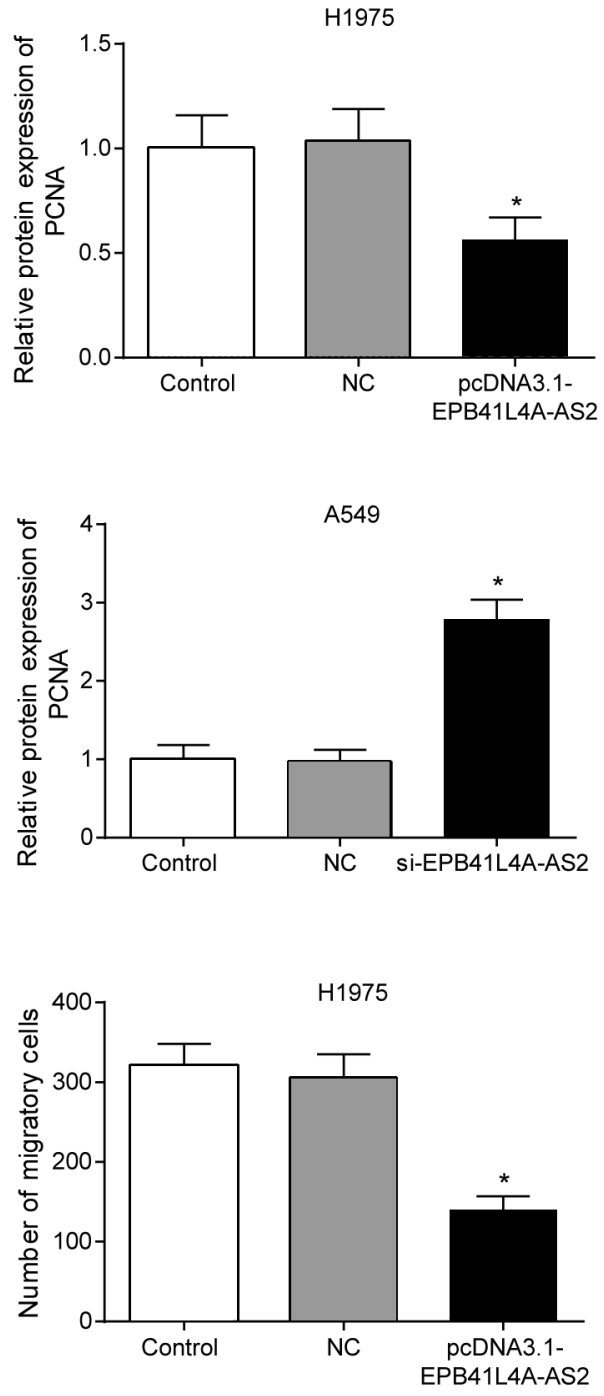

A549

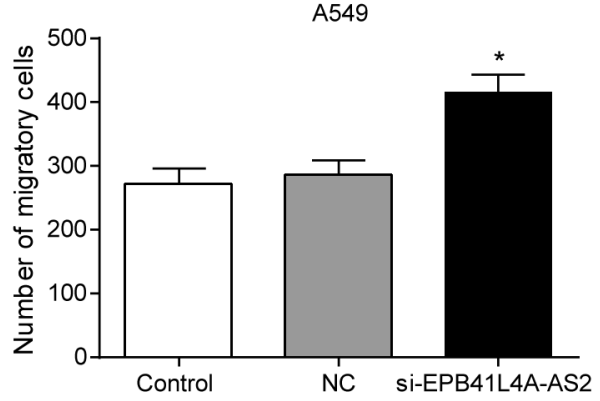

Figure 4. EPB41L4A-AS2 inhibits cell invasion. (A) The level of PCNA protein was detected by western blot. (B) Transwell assay assessed the invasive ability of $\mathrm{H1975}$ and A549 cells (200×). Control: without transfection, NC: transfected with pcDNA3.1 blank plasmid or negative control siRNA, EPB41L4A-AS2: transfected with pcDNA3.1-EPB41L4A-AS2 plasmid, si-EPB41L4A-AS2: transfected with EPB41L4A-AS2 siRNA. ${ }^{*}$ p $<0.05$ compared with control groups. 
A
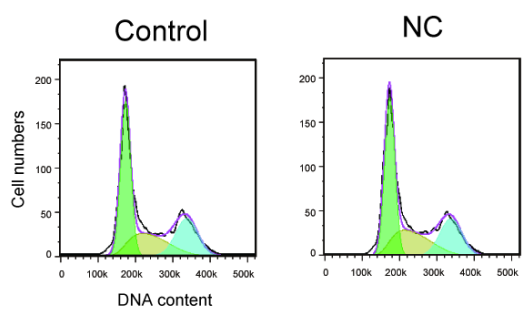

A549

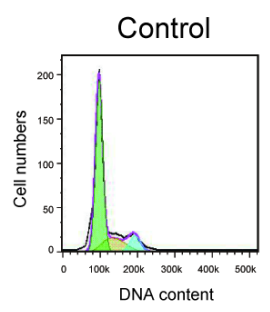

B
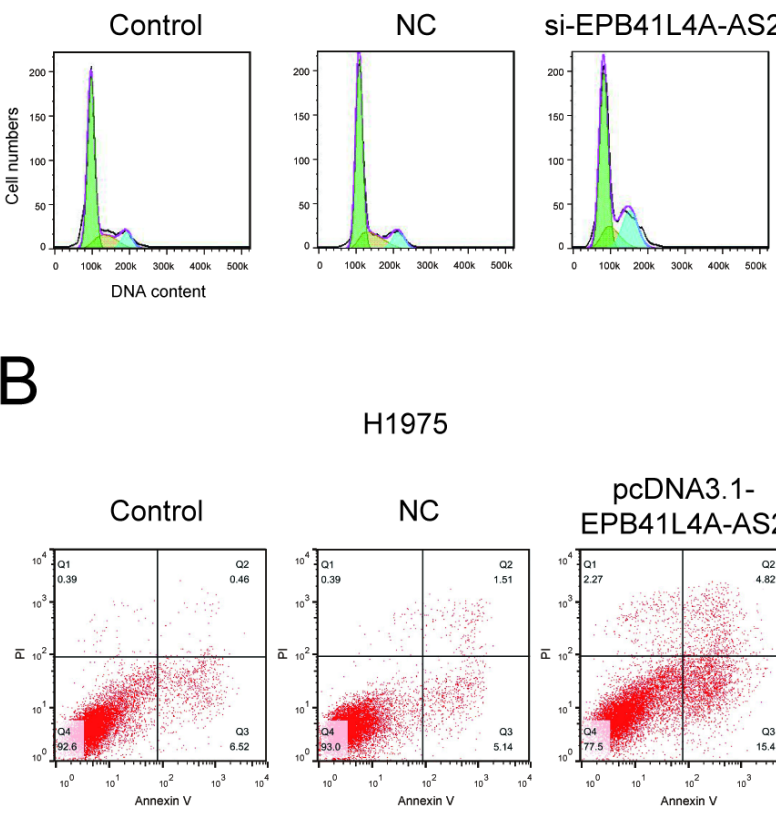

H1975
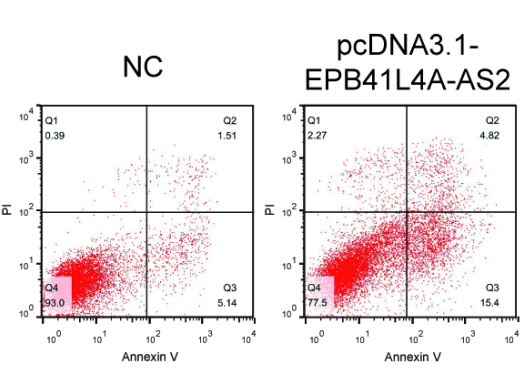

A549
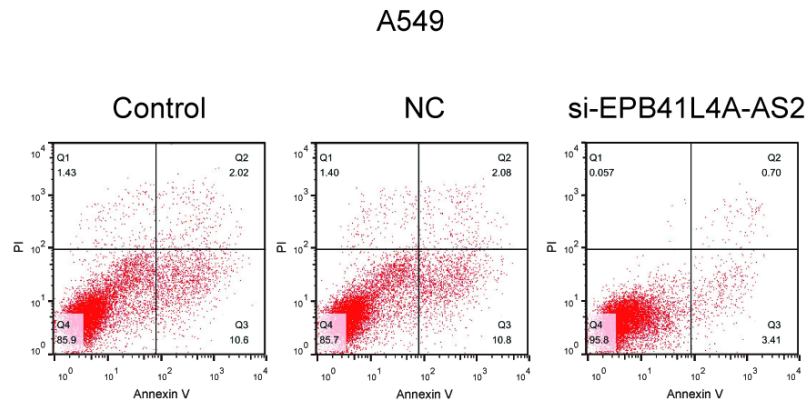
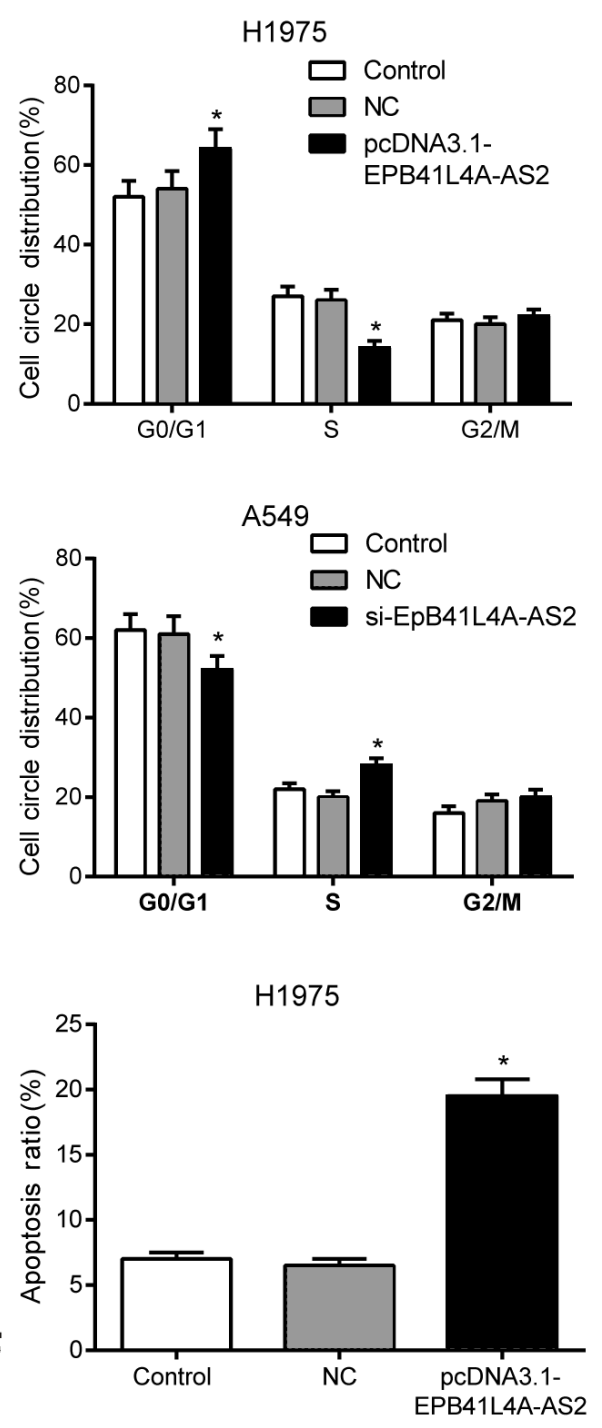

H1975

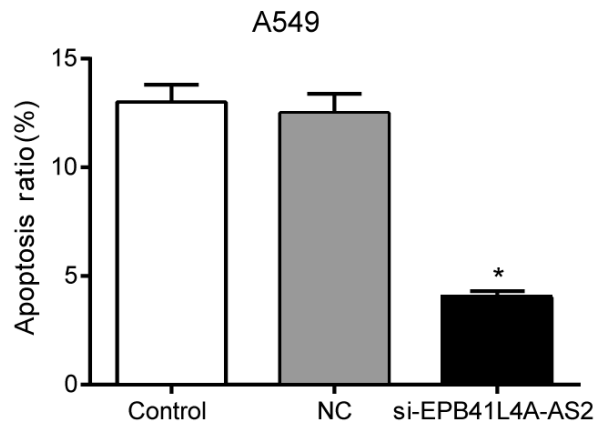

Figure 5. EPB41L4A-AS2 regulates cell cycle and promotes cell apoptosis. (A) EPB41L4A-AS2 induced G0/Gl arrest in NSCLC cells. (B) Annexin V/PI staining and flow cytometry were used to prove the function of EPB41L4A-AS2 on apoptosis in H1975 cells. Control: without transfection, NC: transfected with pcDNA3.1 blank plasmid or negative control siRNA, EPB41L4A-AS2: transfected with pcDNA3.1-EPB41L4A-AS2 plasmid, si-EPB41L4AAS2: transfected with EPB41L4A-AS2 siRNA. ${ }^{*} \mathrm{p}<0.05$ compared with control groups. 
Our results further revealed that EPB41L4A-AS2 expression in cancer tissues was lower than in adjacent tissues, and this corresponds with $\mathrm{Xu}$ et al's. finding that it is also down-regulated in both lung and renal cancers compared to the normal tissues [20]. The down-regulation of EPB41L4AAS2 could also contribute to NSCLC progression and tumorigenesis. Aberrant expression of lncRNA EPB41L4AAS2 in NSCLC suggests it could serve as a tumor suppressor gene.

In addition, CCK- 8 assay and transwell assay indicated that over-expression of EPB41L4A-AS2 could significantly suppress H1975 cell viability and inhibit tumor cells invasion. Xu. et al. also confirmed that lung, renal and breast cancer patients with higher EPB41L4A-AS2 expression had better overall survival with different stratifications; including smoking history, tumor tissue histology, gender and chemotherapy status [20]. While prognostic analysis further strengthened the results of our experiments, very few studies have focused on EPB41L4A-AS2 in other cancers.

Antisense lncRNAs transcribed from the opposed strand to the coding gene $[34,35]$ could act as ecdemic regulators to increase mRNA stability or to interface transcription of the coding gene [36, 37]. EPB41L4A-AS2 has not yet been studied as a novel antisense lncRNA in NSCLC, and it would be very rewarding to explore if EPB41L4A-AS2 can regulate its correlated mRNA expression or influence progress in NSCLC patients.

Although our research with a series of in vitro assays on NSCLC cell lines has shown that over-expression of EPB41L4A-AS2 can inhibit NSCLC proliferation and accelerate cells apoptosis, the EPB41L4A-AS2 target and pathway remain unresolved. Therefore, further investigation of EPB41L4A-AS2's potential mechanism in tumor biology is imperative. In addition, PCNA is commonly used in grading different neoplasms, such as astrocytoma, and it is therefore extremely valuable in diagnosis and prognostication [38]. Images of PCNA nuclear distribution can be used to differentiate the early, mid and late cell-cycle $S$ phase [39]. Moreover, research on DNA replication and restoration in living cells can be enhanced by introducing PCNA translational fusions which would offer the excellent advantage of application in in situ living tissues, and it especially distinguishes between cells in the process of replication and cells undergoing repair [40]. One study also proved that PCNA is a potential therapeutic target in cancer therapy [41] and we confirmed that PCNA decreased in the EPB41L4A-AS2 over-expressing group. This clearly indicates that EPB41L4A-AS2 has a role in regulating the proliferation of NSCLC cells.

In conclusion, we investigated the relationship between EPB41L4A-AS2 and NSCLC and identified that EPB41L4AAS2 can act as a tumor suppressor and inhibit NSCLC progress. These results provide a new direction for studies on the underlying mechanism of NSCLC and therefore offer more effective molecular treatment.

\section{References}

[1] CHEN W, ZHENG R, BAADE PD, ZHANG S, ZENG H et al. Cancer statistics in China, 2015. CA Cancer J Clin 2016; 66: 115-132. https://doi.org/10.3322/caac.21338

[2] TORRE LA, BRAY F, SIEGEL RL, FERLAY J, LORTETTIEULENT J et al. Global cancer statistics, 2012. CA Cancer J Clin 2015; 65: 87-108. https://doi.org/10.3322/caac.21262

[3] LI C, ZHANG S, LU Y, ZHANG Y, WANG E et al. The roles of Notch3 on the cell proliferation and apoptosis induced by CHIR99021 in NSCLC cell lines: a functional link between Wnt and Notch signaling pathways. PLoS One 2013; 8: e84659. https://doi.org/10.1371/journal.pone.0084659

[4] DELA CRUZ CS, TANOUE LT, MATTHAY RA. Lung cancer: epidemiology, etiology, and prevention. Clin Chest Med 2011; 32: 605-644. https://doi.org/10.1016/j. ccm.2011.09.001

[5] KLEBE S, HENDERSON DW. Facts and fiction: premalignant lesions of lung tissues. Pathology 2013; 45: 305-315. https://doi.org/10.1097/PAT.0b013e32835f45fd

[6] SIEGEL R, DESANTIS C, VIRGO K, STEIN K, MARIOTTO A et al. Cancer treatment and survivorship statistics, 2012. CA Cancer J Clin 2012; 62: 220-241. https://doi. org/10.3322/caac. 21149

[7] CANCER GENOME ATLAS RESEARCH NETWORK, WEINSTEIN JN, COLLISSON EA, MILLS GB, SHAW KR et al. The Cancer Genome Atlas Pan-Cancer analysis project. Nat Genet 2013; 45: 1113-1120. https://doi.org/10.1038/ ng. 2764

[8] DERRIEN T, JOHNSON R, BUSSOTTI G, TANZER A, DJEBALI $S$ et al. The GENCODE v7 catalog of human long noncoding RNAs: analysis of their gene structure, evolution, and expression. Genome Res 2012; 22: 1775-1789. https:// doi.org/10.1101/gr.132159.111

[9] DJEBALI S, DAVIS CA, MERKEL A, DOBIN A, LASSMANN $\mathrm{T}$ et al. Landscape of transcription in human cells. Nature 2012; 489: 101-108. https://doi.org/10.1038/nature11233

[10] NAGANO T, FRASER P. No-nonsense functions for long noncoding RNAs. Cell 2011; 145: 178-181. https://doi. org/10.1016/j.cell.2011.03.014

[11] SPIZZO R, ALMEIDA MI, COLOMBATTI A, CALIN GA. Long non-coding RNAs and cancer: a new frontier of translational research? Oncogene 2012; 31: 4577-4587. https:// doi.org/10.1038/onc.2011.621

[12] LIU JY, YAO J, LI XM, SONG YC, WANG XQ et al. Pathogenic role of lncRNA-MALAT1 in endothelial cell dysfunction in diabetes mellitus. Cell Death Dis 2014; 5: e1506. https://doi.org/10.1038/cddis.2014.466

[13] OUNZAIN S, PEZZUTO I, MICHELETTI R, BURDET F, SHETA R et al. Functional importance of cardiac enhancer-associated noncoding RNAs in heart development and disease. J Mol Cell Cardiol 2014; 76: 55-70. https://doi. org/10.1016/j.yjmcc.2014.08.009

[14] CHENG N, LI X, ZHAO C, REN S, CHEN X et al. Microarray expression profile of long non-coding RNAs in EGFRTKIs resistance of human non-small cell lung cancer. Oncol Rep 2015; 33: 833-839. https://doi.org/10.3892/or.2014.3643 
[15] XU TP, HUANG MD, XIA R, LIU XX, SUN M et al. Decreased expression of the long non-coding RNA FENDRR is associated with poor prognosis in gastric cancer and FENDRR regulates gastric cancer cell metastasis by affecting fibronectin1 expression. J Hematol Oncol 2014; 7: 63. https:// doi.org/10.1186/s13045-014-0063-7

[16] VIKRAM R, RAMACHANDRAN R, ABDUL KS. Functional significance of long non-coding RNAs in breast cancer. Breast Cancer 2014; 21: 515-521. https://doi.org/10.1007/ s12282-014-0554-y

[17] LIN CY, XU HM. Novel perspectives of long non-coding RNAs in esophageal carcinoma. Carcinogenesis 2015; 36: 1255-1262. https://doi.org/10.1093/carcin/bgv136

[18] SUN M, NIE FQ, WANG ZX, DE W. Involvement of lncRNA dysregulation in gastric cancer. Histol Histopathol 2016; 31 : 33-39. https://doi.org/10.14670/HH-11-655

[19] OTA T, SUZUKI Y, NISHIKAWA T, OTSUKI T, SUGIYAMA $\mathrm{T}$ et al. Complete sequencing and characterization of 21,243 full-length human cDNAs. Nat Genet 2004; 36: 40-45. https://doi.org/10.1038/ng1285

[20] XU S, WANG P, YOU Z, MENG H, MU G et al. The long non-coding RNA EPB41L4A-AS2 inhibits tumor proliferation and is associated with favorable prognoses in breast cancer and other solid tumors. Oncotarget 2016; 7: 20704 20717. https://doi.org/10.18632/oncotarget. 8007

[21] LIPOVICH L, JOHNSON R, LIN CY. MacroRNA underdogs in a microRNA world: evolutionary, regulatory, and biomedical significance of mammalian long non-proteincoding RNA. Biochim Biophys Acta 2010; 1799: 597-615. https://doi.org/10.1016/j.bbagrm.2010.10.001

[22] CHEN LL, CARMICHAEL GG. Long noncoding RNAs in mammalian cells: what, where, and why? Wiley Interdiscip Rev RNA 2010; 1: 2-21. https://doi.org/10.1002/wrna.5

[23] KAPRANOV P, CHENG J, DIKE S, NIX DA, DUTTAGUPTA R et al. RNA maps reveal new RNA classes and a possible function for pervasive transcription. Science 2007; 316: 1484-1488. https://doi.org/10.1126/science.1138341

[24] CARNINCI P, KASUKAWA T, KATAYAMA S, GOUGH J, FRITH MC et al. The transcriptional landscape of the mammalian genome. Science 2005; 309: 1559-1563. https://doi. org/10.1126/science.1112014

[25] MASROOR M, MIR R, JAVID J, PRASANT Y, IMTIYAZ A et al. Cell Free EGFR mRNA Expression and Implications for Survival and Metastasis in Non-Small Cell Lung Cancer Cases. Asian Pac J Cancer Prev 2015; 16: 6445-6449.

[26] YANG Z, GUO Q, WANG Y, CHEN K, ZHANG L et al. AZD3759, a BBB-penetrating EGFR inhibitor for the treatment of EGFR mutant NSCLC with CNS metastases. Sci Transl Med 2016; 8: 368ra172. https://doi.org/10.1126/scitranslmed.aag0976

[27] LIANG W, LV T, SHI X, LIU H, ZHU Q et al. Circulating long noncoding RNA GAS5 is a novel biomarker for the diagnosis of nonsmall cell lung cancer. Medicine (Baltimore) 2016; 95: e4608. https://doi.org/10.1097/MD.0000000000004608

[28] QI P, DU X. The long non-coding RNAs, a new cancer diagnostic and therapeutic gold mine. Mod Pathol 2013; 26: 155-165. https://doi.org/10.1038/modpathol.2012.160
[29] LI H, YU B, LI J, SU L, YAN M et al. Overexpression of lncRNA H19 enhances carcinogenesis and metastasis of gastric cancer. Oncotarget 2014; 5: 2318-2329. https://doi. org/10.18632/oncotarget.1913

[30] AUGOFF K, MCCUE B, PLOW EF, SOSSEY-ALAOUI K. miR-31 and its host gene lncRNA LOC554202 are regulated by promoter hypermethylation in triple-negative breast cancer. Mol Cancer 2012; 11: 5. https://doi.org/10.1186/14764598-11-5

[31] YANG Y, LI H, HOU S, HU B, LIU J et al. The noncoding RNA expression profile and the effect of lncRNA AK126698 on cisplatin resistance in non-small-cell lung cancer cell. PLoS One 2013; 8: e65309. https://doi.org/10.1371/journal. pone.0065309

[32] SCHMIDT LH, SPIEKER T, KOSCHMIEDER S, SCHAFFERS S, HUMBERG J et al. The long noncoding MALAT-1 RNA indicates a poor prognosis in non-small cell lung cancer and induces migration and tumor growth. J Thorac Oncol 2011; 6: 1984-1992. https://doi.org/10.1097/ JTO.0b013e3182307eac

[33] LIU XH, LIU ZL, SUN M, LIU J, WANG ZX et al. The long non-coding RNA HOTAIR indicates a poor prognosis and promotes metastasis in non-small cell lung cancer. BMC Cancer 2013; 13: 464. https://doi.org/10.1186/1471-2407-13464

[34] PANG KC, FRITH MC, MATTICK JS. Rapid evolution of noncoding RNAs: lack of conservation does not mean lack of function. Trends Genet 2006; 22: 1-5. https://doi. org/10.1016/j.tig.2005.10.003

[35] KATAYAMA S, TOMARU Y, KASUKAWA T, WAKI K, NAKANISHI $M$ et al. Antisense transcription in the mammalian transcriptome. Science 2005; 309: 1564-1566. https:// doi.org/10.1126/science.1112009

[36] MORRIS KV, VOGT PK. Long antisense non-coding RNAs and their role in transcription and oncogenesis. Cell Cycle 2010; 9: 2544-2547. https://doi.org/10.4161/cc.9.13.12145

[37] YU W, GIUS D, ONYANGO P, MULDOON-JACOBS K, KARP J et al. Epigenetic silencing of tumour suppressor gene p15 by its antisense RNA. Nature 2008; 451: 202-206. https:// doi.org/10.1038/nature06468

[38] ZHANG K, LI C, LIU Y, LI L, MENG X et al. Evaluation of astrocytoma cell proliferation using diffusion-weighted imaging: correlation with expression of proliferating cell nuclear antigen. Transl Neurosci 2015; 6: 265-270. https:// doi.org/10.1515/tnsci-2015-0029

[39] SCHONENBERGER F, DEUTZMANN A, FERRANDOMAY E, MERHOF D. Discrimination of cell cycle phases in PCNA-immunolabeled cells. BMC Bioinformatics 2015; 16: 180. https://doi.org/10.1186/s12859-015-0618-9

[40] HERCE HD, RAJAN M, LATTIG-TUNNEMANN G, FILLIES M, CARDOSO MC. A novel cell permeable DNA replication and repair marker. Nucleus 2014; 5: 590-600. https:// doi.org/10.4161/nucl.36290

[41] WANG SC. PCNA: a silent housekeeper or a potential therapeutic target? Trends Pharmacol Sci 2014; 35: 178-186. https://doi.org/10.1016/j.tips.2014.02.004 